\title{
Aislamiento, Caracterización y Selección de Bacterias Lácticas Autóctonas de Leche y Queso Fresco Artesanal de Cabra
}

\author{
Carolina Ramírez-López y Jorge F. Vélez-Ruiz \\ Departamento de Ingeniería Química, Alimentos y Ambiental, Universidad de las Américas Puebla, \\ Ex Hacienda Sta. Catarina Mártir S/N, Cholula, Puebla. C.P.72810. México. \\ (e-mail: jorgef.velez@udlap.mx; carolina.ramirezlz@udlap.mx)
}

Recibido Mar. 17 2016; Aceptado May. 3, 2016; Versión final Jun. 13, 2016, Publicado Dic. 2016

\begin{abstract}
Resumen
Se aislaron y caracterizaron 18 cepas autóctonas de bacterias con el objetivo de seleccionar aquellas con características funcionales definidas para ser utilizadas como cultivos iniciadores en la producción de queso fresco. La investigación se dividió en tres etapas: (1) evaluación de las características funcionales (actividad proteolítica, actividad lipolítica, capacidad acidificante y producción de gas); (2) selección e identificación fenotípica de las cepas y (3) validación de su aplicación como cultivos iniciadores a nivel de laboratorio (pruebas de antagonismo y cinética de crecimiento en leche). Los géneros identificados fueron Lactobacillus (56\%), Lactococcus (22\%) y Leuconostoc (22\%), que presentaron bajo poder acidificante, sin producción de gas y sólo 3 de las 18 cepas presentaron actividad lipolítica, mientras que la mayoría desarrolló actividad proteolítica. A partir de los parámetros cinéticos evaluados, es posible inferir el desempeño de las cepas lácticas, permitiendo con ello mejorar el control sobre los procesos, la vida útil y la calidad microbiológica del producto lácteo terminado.
\end{abstract}

\section{Isolation, Characterization and Selection of Autochthonous Lactic Acid Bacteria from Goat Milk and Fresh Artisanal-Goat Cheese}

\begin{abstract}
Eighteen indigenous strains of bacteria were isolated and characterized in order to select those with defined functional characteristics, to be utilized as starter cultures in the production of fresh cheese. The research was divided into three stages: (1) evaluation of functional characteristics (proteolytic activity, lipolytic activity, acidifying capacity and gas production); (2) selection and phenotypic identification of strains and (3) validation of their application as starter cultures at laboratory scale (tests of antagonism and growth kinetics in milk). Lactobacillus (56\%), Lactococcus $(22 \%)$ and Leuconostoc $(22 \%)$ were the genders identified, they showed low acidifying power, without gas production and only 3 of 18 strains presented lipolytic activity, whereas most of them developed proteolytic activity. From the kinetic parameters calculated in this study is possible to determine the performance of the strains allowing to better control the process, increase the shelf life and quality of the final milk product.
\end{abstract}

Keywords: autochthonous strains; lactic acid bacteria; fresh cheese; starter culture. 


\section{INTRODUCCIÓN}

Actualmente diversos alimentos, entre ellos el queso, se elaboran con cultivos iniciadores comerciales, los cuales han sido aislados y seleccionados con base a algunas propiedades deseadas tales como la producción de sabores y aromas, la modificación de textura y la protección contra el deterioro ocasionado por otros microorganismos (Leroy y De Vuyst, 2004; Asteri et al., 2009; Vásquez et al., 2009; Karimi et al., 2012). No obstante, se reconoce que el uso de cultivos comerciales puede conducir a la pérdida de características típicas de los quesos artesanales debido al reemplazo de la compleja microbiota nativa (Piraino et al., 2008; Pavunc et al., 2012).

Sin embargo, no todas las cepas que constituyen la microflora presente en el queso tienen función relevante en términos de conferir atributos de protección, generación de aromas y sabor o modificación de textura (Pavunc et al., 2012; Speranza et al., 2015). Es por ello que el aislamiento y caracterización de las cepas de bacterias ácido lácticas (BAL) provenientes de productos artesanales tiene gran importancia; ya que permite incrementar el conocimiento acerca del potencial y de la aplicación de cepas autóctonas para ser utilizadas como cultivos iniciadores. De esta manera se busca mejorar y optimizar el control de los procesos de fermentación, permitiendo desarrollar productos con propiedades definidas y constantes (Speranza et al., 2015).

Diferentes autores han aislado bacterias lácticas autóctonas a partir de leche de cabra (Alonso-Calleja et al., 2002; Nikolic et al., 2008; González y Zárate, 2012; Perin y Nero, 2014) y quesos artesanales (Cogan et al., 1997; Pérez-Erlotondo et al., 1998; Fraga-Cotelo et al., 2013; Terzic-Vidojevic et al., 2014), con el objetivo de identificarlas y caracterizar sus propiedades funcionales o tecnológicas en los procesos de elaboración y maduración de quesos; o bien con la intención de incluirlas como cultivos iniciadores, posibilitando la producción industrial de quesos con características similares a las artesanales. La selección de cepas autóctonas con propiedades deseables podría lograr una producción estandarizada, mejorar la calidad sensorial y al mismo tiempo preservar las características que definen la identidad de un queso artesanal (Pavunc et al., 2012; Speranza et al., 2015). De esta manera, el objetivo de este estudio fue aislar, caracterizar y seleccionar algunas cepas autóctonas provenientes de leche y queso de cabra, para ser utilizadas como cultivos iniciadores en la producción de queso fresco.

\section{MATERIALES Y MÉTODOS}

Se describe la materia prima usada y luego se explica cómo se realiza el aislamiento de bacterias lácticas de leche y queso fresco de cabra, la conservación de las cepas, y el tipo de fermentación usado. Se detalla cómo se realizó la caracterización funcional de las cepas, la caracterización fenotípica de las cepas, y la selección de cepas con uso potencial como cultivos iniciadores en queso fresco, para explicar finalmente la determinación de los parámetros cinéticos

\section{Materia prima}

Se realizaron aislamientos a partir de leche cruda y queso fresco artesanal de cabra. Las muestras de leche fueron colectadas directamente de un hato caprino (Rancho El Sahuaro, Tecamachalco, Puebla, México), de la misma manera que para el queso; durante el primer semestre del año, bajo condiciones extremas de higiene, las muestras fueron transportadas al laboratorio en hielera, donde permanecieron en refrigeración ( 4 a $\left.7^{\circ} \mathrm{C}\right)$ por no más de 24 horas hasta su análisis.

\section{Aislamiento de bacterias lácticas de leche y queso fresco de cabra}

Las bacterias ácido lácticas (BAL) se caracterizan por ser bacterias Gram-positivas, catalasa negativas, y anaerobio-facultativas (Settanni y Moschetti, 2010). Para su aislamiento se ha reportado el uso de diferentes medios de cultivo; Man Rogosa Sharpe (MRS) y Rogosa Agar (LBS) para Lactobacillus spp. (DeMan et al., 1972 y Rogosa et al., 1951); M17 para Lactococcus spp. (Terzaghi y Sandine, 1975); y el medio MSE para Leuconostoc spp. (Mayeux et al., 1962). Utilizando éstos medios y variando las condiciones de incubación es posible realizar un aislamiento dirigido de BAL, en que los géneros más importantes son; Lactobacillus, Lactococcus, Pediococcus y Leuconostoc (Leroy y De Vuyst, 2004). A partir de porciones representativas $(10 \mathrm{~g})$ de cada muestra, homogenizadas durante $5 \mathrm{~min}$ con $90 \mathrm{~mL}$ de un solución diluyente $\left(8.5 \mathrm{~g} \mathrm{~L}^{-1} \mathrm{de}\right.$ $\mathrm{NaCl}$ y $1 \mathrm{~g} \mathrm{~L}^{-1}$ de peptona), se prepararon diluciones seriadas $\left(10^{-1}\right.$ a $\left.10^{-6}\right)$, las cuales se inocularon por vertido en placa utilzando diferentes medios de cultivo, todos de la marca BD Difcoß (Becton Dickinson France S.A., Le Pont de Claix, Francia): LBS y MRS para Lactobacillus, M17 para Lactococcus y MSE para Leuconostoc. Se incubaron a $35^{\circ} \mathrm{C}$ por 24 a 48 horas en atmósfera microaerofílica $\left(5 \%\right.$ de $\left.\mathrm{O}_{2}\right)$, utilizando sobres generadores de condiciones anaerobias (BD GasPak® EZ Gas Generating Systems, Baltimore, MD, USA). 


\section{Conservación de las cepas}

Las cepas aisladas fueron conservadas en caldo MRS o M17, suplementado con glicerol al $30 \%$ y se almacenaron a $-70^{\circ} \mathrm{C}$ en viales para crio-preservación. Antes de cada ensayo las cepas fueron incubadas en su medio óptimo a $35^{\circ} \mathrm{C}$ por $24 \mathrm{~h}$, para reconstituirlas.

\section{Tipo de fermentación (homo y heteroláctica)}

A partir de un cultivo puro, cada cepa fue sembrada por estría en un medio mejorado propuesto por Zúñiga, et al. (1993), para la identificación y diferenciación de BAL como homo y heterolácticas (medio M5 formulado con fructosa como fuente de carbono), posteriormente se incubaron a $35^{\circ} \mathrm{C}$ en condiciones microaerofílicas. Se consideran BAL homolácticas aquellas colonias azul-verdoso con vire del medio de azul a amarillo, mientras que las BAL heterolácticas son aquellas colonias de color blanco que no provocan cambio de color en el medio, es decir el medio permanece azul, tal como se observa en la Figura 1.
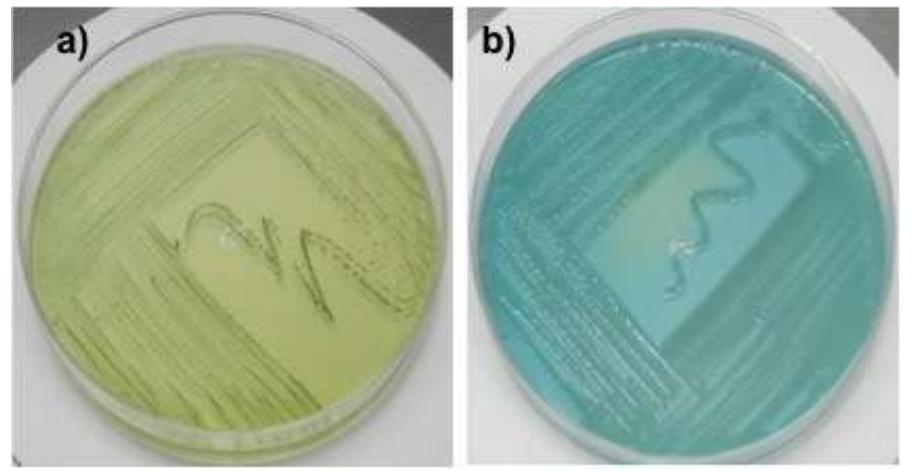

Fig. 1: Diferenciación del tipo de fermentación realizado por BAL: a) Homoláctica y b) Heteroláctica.

\section{Caracterización funcional de las cepas}

Las pruebas de caracterización tecnológica consistieron en la determinación cualitativa de: la actividad proteolítica-acidificante, la actividad lipolítica y la producción de gas, todos los análisis fueron realizados por duplicado.

a) Actividad proteolítica-acidificante: La determinación de la actividad proteolítica-acidificante para cada una de las 18 cepas lácticas autóctonas se determinó en tubos de ensayo con $10 \mathrm{~mL}$ de medio Litmus milk BD Difco® (Becton Dickinson France S.A., Le Pont de Claix, Francia), el cuál se inoculó con $200 \mu \mathrm{L}$ de una suspensión bacteriana a una concentración 3 MacFarland $\left(9.0 \times 10^{8} \mathrm{UFC} / \mathrm{mL}\right)$. La incubación se efectuó durante 7 días a $30^{\circ} \mathrm{C}$, realizando la lectura diaria de los tubos (Nikolic et al., 2008). La diferenciación se basa en la producción de ácidos y en la coagulación y/o proteólisis de caseína por acción de las bacterias lácticas. La adición a la leche del "Litmus", un indicador de pH y óxido-reducción, extiende su utilidad como medio diferencial permitiendo observar diferentes reacciones (Figura 2). La reacción es ácida cuando el medio vira de azul-púrpura a rosado-rojo debido a la fermentación de la lactosa y la glucosa. La reacción es alcalina cuando el microorganismo ataca las sustancias nitrogenadas presentes en el medio, formando amoníaco o aminas, el color del medio permanece sin cambios. Mientras que la reducción ocurre cuando el oxígeno es eliminado del "Litmus" por acción de la enzima reductasa, generándose una decoloración del medio. Por otro lado la coagulación indica la precipitación de la caseína por acción ácida y en la digestión se observa una clarificación del medio y la disolución de la cuajada por digestión de la caseína.

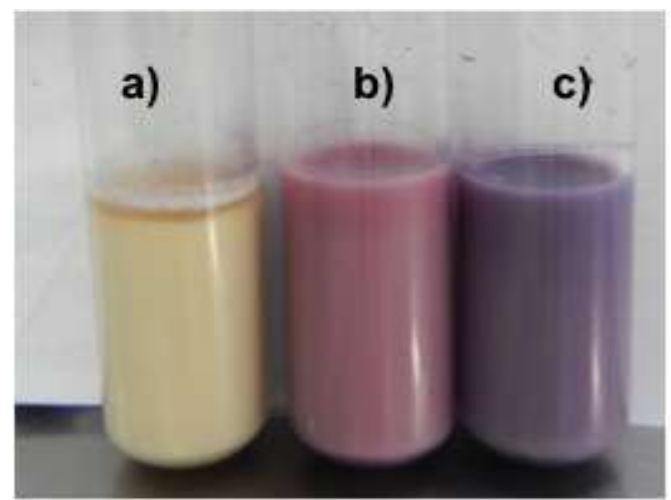

Fig. 2: Reacciones en medio Litmus milk a las 24 horas de cultivo: Reducción, b) Reacción ácida y c) Reacción alcalina 
b) Actividad lipolítica: Para evaluar la capacidad lipolítica de las BAL se utilizó el método reportado por Morais (2004), el cual consistió en sembrar la cepa correspondiente en agar nutritivo con $1 \%$ de nata añadida (aproximadamente $36 \%$ de materia grasa), e incubar a $30^{\circ} \mathrm{C}$ por 72 horas. Al término de este tiempo se revisaron las placas a contra luz para observar la presencia de un halo alrededor de la colonia, que es indicativo de la degradación de grasa o lipólisis positiva.

c) Producción de gas: Para detectar la capacidad de producción de gas de las cepas de BAL, se usaron tubos de ensayo con $10 \mathrm{~mL}$ de caldo nutritivo suplementado con lactosa al $5 \%$, y se adicionaron $100 \mu \mathrm{L}$ de cultivo de la cepa correspondiente a una concentración 3 MacFarland $\left(9.0 \times 10^{8} \mathrm{UFC} / \mathrm{mL}\right)$, se mezcló perfectamente con ayuda de un vortex y se colocó cuidadosamente una campana de Durham deslizándola por las paredes del tubo hasta que ésta se llenara completamente del medio. Posteriormente los tubos se incubaron durante 4 días a $30^{\circ} \mathrm{C}$. La producción de gas en el medio líquido fue registrada de acuerdo al grado en el que la campana Durham se llenó de gas, según la siguiente escala: $0=$ ausencia de gas en la campana Durham; 1 = presencia de burbuja en la punta de la campana; $2=1 / 3$ de la campana llena con gas; $3=2 / 3$ de la campana con gas; 4 = campana Durham completamente llena de gas.

\section{Caracterización fenotípica de las cepas BAL aisladas mediante pruebas bioquímicas}

La identificación fenotípica de las cepas BAL aisladas, se realizó mediante el sistema de galerías estandarizado, API $50 \mathrm{CH}$ (BioMérieux, Inc., Hazelwood Missouri, E.U.), destinado al estudio del metabolismo de hidratos de carbono para la identificación del género Lactobacillus y otros microorganismos próximos (De Roissart y Luquet, 1994). Las galerías están formadas por 50 microtubos API distribuidos en 5 columnas (10 microtubos $\mathrm{c} / \mathrm{u}$ ). El primer microtubo sirve como control negativo y los siguientes contienen un azúcar diferente. En los ensayos de fermentación se inoculan con el medio API 50 CHL que rehidrata los sustratos contenidos. La adición del inóculo al medio $50 \mathrm{CHL}$, el llenado de los microtubos e incubación de las galerías, se realizó de acuerdo con la metodología descrita en la ficha técnica del sistema API 50 CHL. La prueba se considera positiva cuando por la acidificación del medio API $50 \mathrm{CHL}$, el púrpura de bromocresol vira a amarillo, y la esculina da un cambio a color negro.

Éstos cambios observables constituyen el perfil bioquímico, por lo que apoyados en el programa informático APIWEB $®$ (BioMerieux SA, Marcy l'E'toile, Francia), suministrado por la casa comercial, permiten la identificación del microorganismo.

\section{Selección de cepas con uso potencial como cultivos iniciadores en queso fresco}

A partir de la caracterización funcional de las cepas de bacterias lácticas y con base al tipo de producto al que se desean aplicar, se seleccionaron 10 cepas a las cuáles se les realizó un estudio más detallado para validar su uso como cultivos iniciadores. Para ello, se realizaron pruebas a nivel de laboratorio de: a) antagonismo cruzado, b) curvas de acidificación y c) cinética de crecimiento en leche.

a) Pruebas de antagonismo cruzado: Para poder utilizar mezclas de cepas como cultivos iniciadores, se realizó la verificación de compatibilidad entre cepas de BAL o de antagonismo cruzado mediante la prueba de difusión en pozos. La preparación del cultivo se realizó usando $100 \mu \mathrm{L}$ de cultivo por cada $30 \mathrm{~mL}$ de caldo, correspondiente a cada microorganismo. Las cajas se prepararon usando agar MRS, BD Difco® (Becton Dickinson France S.A., Le Pont de Claix, Francia), vertiendo primero una capa delgada y dejando solidificar, posteriormente se colocaron de forma equidistante 5 penicilindros de acero inoxidable de $8 \mathrm{~mm}$ de diámetro y se añadió más agar hasta cubrir la mitad de la altura del penicilindro. Una vez que solidificó el agar, por medio de pinzas estériles se retiraron los penicilindros y se agregaron $100 \mu \mathrm{L}$ del sobrenadante correspondiente libre de células, en cada uno de los pozos. Posteriormente, las cajas permanecieron en refrigeración $\left(4^{\circ} \mathrm{C}\right)$ toda la noche para permitir la difusión de la muestra y luego se incubaron a $30^{\circ} \mathrm{C}$ por 24 horas, transcurrido este periodo, se corroboró la inhibición de crecimiento por la presencia de halos.

b) Curvas de acidificación: Para realizar las curvas de acidificación se siguió el protocolo propuesto por la Federación Internacional de Lácteos (IDF, 1995), el cual consistió en inocular la cepa a avaluar (1\%), previamente estandarizada a una concentración equivalente a 4 MacFarland $\left(1.2 \times 10^{9} \mathrm{UFC} / \mathrm{mL}\right)$ en $100 \mathrm{~mL}$ de leche entera ultrapasteurizada (UHT). Posteriormente se incubó a $30^{\circ} \mathrm{C}$ y se monitoreó el descenso de $\mathrm{pH}$ y la generación de ácido láctico a las $0,12,24$ y 48 horas. El pH de las muestras se determinó a temperatura ambiente $\left(22 \pm 2^{\circ} \mathrm{C}\right)$ con un potenciómetro (Conductronic S.A., Puebla, México) por inmersión del electrodo previamente calibrado. Mientras que el valor de acidez se determinó por titulación con $\mathrm{NaOH}$ $0.1 \mathrm{~N}$ siguiendo el método oficial 920.124 de la A.O.A.C. (2005), expresado como porcentaje de ácido láctico en leche.

c) Cinética de crecimiento en leche: Para conocer el comportamiento de cada una de las cepas BAL en leche, se realizó otro procedimiento. Se inocularon $100 \mathrm{~mL}$ de leche pasteurizada con $1 \mathrm{~mL}$ de agua 
peptonada adicionada con una población de $10^{3} \mathrm{UFC} / \mathrm{mL}$ de la cepa a evaluar. Para monitorear el cambio en el recuento $\left(\log _{10}\right.$ UFC g-1) como función del tiempo, se tomaron muestras a las: 0, 3, 6 12, 24, 48 y 72 h y se sembraron las diluciones adecuadas en agar MRS y M17 para Lactobacillus y Lactococcus, respectivamente, incubando a $35^{\circ} \mathrm{C}$ por 24 a $48 \mathrm{~h}$ en condiciones de anaerobiosis. Se realizó el conteo celular y se construyó la curva de crecimiento. La lectura del conteo en placa se realizó diferenciando a nivel macroscópico, las colonias características de cada cultivo iniciador, por su tamaño y color. Colonias pequeñas de color blanco con diámetros menores a $3 \mathrm{~mm}$ corresponden a Lactococcus, mientras que colonias grandes de color crema con diámetros mayores a $3 \mathrm{~mm}$ corresponden a Lactobacillus. Adicional a esto se llevó a cabo la verificación microscópica donde se identificó el crecimiento del lactococos como cadenas de forma esférica y el de lactobacilos por su forma de bastones (Sun-Waterhouse et al., 2013).

\section{Determinación de parámetros cinéticos}

Velocidad máxima de acidificación: A partir de las curvas de $\mathrm{pH}$ en función del tiempo, se calculó la velocidad máxima de acidificación $(\mathrm{Vm})$ de acuerdo a la ecuación (1), donde $\Delta \mathrm{pH}$ es el cambio de $\mathrm{pH}$ y $\Delta \mathrm{t}$ es el tiempo transcurrido.

$$
V m=\left(\frac{p H}{t}\right)_{m a ́ x}
$$

Cinética de crecimiento: Para cada curva de crecimiento de las cepas seleccionadas se realizó un ajuste utilizando el modelo de crecimiento primario de Baranyi y Roberts (1994) y el modelo lineal (Rosso et al., 1995), disponibles en la edición web de DMFit versión 3.0 (Institute of Food Research, Norwich, Reino Unido) ingresando desde la dirección http://browser.combase.cc/DMFit.aspx. Mediante este programa computacional se realizaron las estimaciones de los siguientes parámetros cinéticos: número inicial ( $\mathrm{N}_{0}$, $\log _{10}$ UFC g ${ }^{-1}$ ), la tasa de crecimiento máxima ( $\mu$ máx, log10 UFC g-1 $\mathrm{h}^{-1}$ ), coeficiente de regresión $\left(R^{2}\right)$ y error estándar del ajuste (ES).

El modelo de crecimiento primario de Baranyi y Roberts (Ec. 2), es un modelo que fundamentado en la dinámica de poblaciones microbianas, que relaciona la velocidad máxima de crecimiento y el tiempo de latencia (fase lag), y que permite cuantificar la cinética de crecimiento microbiano para obtener diferentes parámetros cinéticos útiles (Cayré et al., 2007; Ferrer et al., 2009).

$$
\frac{d N_{(t)}}{d t}=\frac{q_{(t)}}{q_{(t)}+1} \cdot{ }_{\text {máx }} \cdot\left[1\left\{\frac{N(t)}{N_{\text {máx }}}\right\}^{m}\right] N_{(t)}
$$

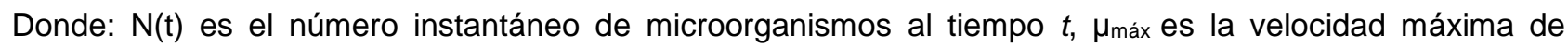
crecimiento, $\mathrm{N}_{\text {máx }}$ es el número máximo de microorganismos que el sistema puede soportar, $\mathrm{m}$ es una constante del modelo.

Formulación de los cultivos iniciadores: Después de la caracterización de las 18 cepas lácticas autóctonas aisladas a partir de leche cruda de cabra y de queso fresco artesanal de cabra, se seleccionaron 5 cepas lácticas de acuerdo a sus aptitudes tecnológicas y compatibilidad de crecimiento. De esta manera, se formularon 2 cultivos mixtos, los cuales fueron evaluados en la producción de queso fresco (datos no incluidos y no publicados). Los cultivos autóctonos experimentales quedaron constituidos de la siguiente forma:

Cultivo artesanal I: una cepa acidificante (11), una lipolítica (6) y una proteolítica (16).

Cultivo artesanal II: dos cepas acidificantes (2 y 11) y una lipolítica (6).

Paralelamente se utilizó un tercer cultivo comercial como referencia: CHOOZIT DVIß (Danisco)

\section{RESULTADOS Y DISCUSIÓN}

En el presente estudio, la leche se obtuvo directamente del hato caprino, mientras que los quesos utilizados para el muestreo fueron elaborados artesanalmente, permitiendo aislar únicamente las BAL que se generan durante la fermentación natural del producto y no por la adición de cultivos iniciadores, como sucede en el caso de un queso comercial. De acuerdo a Karimi et al. (2012). el éxito para el aislamiento de BAL puede atribuirse a diversos factores, entre los que destacan las condiciones higiénicas de la ordeña y el estado de maduración del queso. A partir de las pruebas realizadas, los resultados de la caracterización de los microorganismos autóctonos aislados, se resumen en la Tabla 1. 
Aislamiento de bacterias lácticas: Se seleccionaron las cepas de BAL tomando en cuenta sus características fenotípicas, tales como la morfología de sus colonias y la observación microscópica después de realizada la tinción Gram. En las placas de agar MRS y LBS, las cepas de Lactobacillus formaron colonias cuyo tamaño fue de 1 a $2 \mathrm{~mm}$, de color blanco cremoso, de forma redonda, puntiformes, con bordes enteros, y superficie convexa, de consistencia butirosa y húmeda; lo que corresponde a características previamente reportadas por Jackson et al. (2002). Mientras que en las placas de M17, las cepas de Lactococcus formaron colonias típicas circulares, compactas, con bordes uniformes y diámetro de $1 \mathrm{a} 3 \mathrm{~mm}$. Por otro lado, las placas con medio MSE permitieron el aislamiento de cepas del género Leuconostoc, cuyas colonias se distinguieron por presentar una consistencia mucoide a causa de la formación de polímeros de dextrano.

Caracterización de las bacterias lácticas aisladas: Se consideraron como BAL aquellas cepas con resultado de catalasa y oxidasa negativas, debido a que en la primera prueba no hubo producción de gas al adicionar $\mathrm{H}_{2} \mathrm{O}_{2}$ y en la segunda no hubo vire de incoloro a azul al agregar el reactivo diclorhidrato de tetrametil-pfenilendiamina (TPD) al 1\%. Con respecto a la morfología microscópica, se identificaron 11 cepas como bacilos Gram positivos y 7 cepas como cocos Gram positivos. De ésta manera, se identificaron presuntivamente a las BAL como cocos o bacilos Gram positivos, catalasa y oxidasa negativos.

Tabla 1: Características microscópicas y funcionales de las cepas aisladas de leche cruda de cabra (LCC) y queso fresco de cabra (QFC).

\begin{tabular}{cclcccccc}
\hline Cepa & Fuente & Tinción Gram & Oxidasa & Catalasa & $\begin{array}{c}\text { Tipo de } \\
\text { Fermentación }\end{array}$ & $\begin{array}{c}\text { Actividad } \\
\text { proteolítica }\end{array}$ & $\begin{array}{c}\text { Actividad } \\
\text { lipolítica }\end{array}$ & $\begin{array}{c}\text { Producción } \\
\text { de gas }\end{array}$ \\
\hline 1 & LCC & Cocos $(+)$ & - & - & Homoláctica & + & - & 0 \\
2 & LCC & Bacilos $(+)$ & - & - & Homoláctica & + & - & 0 \\
3 & QFC & Cocos (+) & - & - & Homoláctica & - & - & 0 \\
4 & QFC & Cocos (+) & - & - & Homoláctica & - & - & 0 \\
5 & LCC & Bacilos (+) & - & - & Homoláctica & - & + & 0 \\
6 & LCC & Bacilos (+) & - & - & Homoláctica & - & + & 0 \\
7 & LCC & Cocos $(+)$ & - & - & Homoláctica & - & - & 0 \\
8 & LCC & Bacilos $(+)$ & - & - & Heteroláctica & + & - & 1 \\
9 & LCC & Bacilos $(+)$ & - & - & Homoláctica & + & - & 0 \\
10 & LCC & Bacilos $(+)$ & - & - & Homoláctica & + & - & 0 \\
11 & LCC & Cocos $(+)$ & - & - & Homoláctica & + & - & 0 \\
12 & LCC & Bacilos $(+)$ & - & - & Homoláctica & + & - & 0 \\
13 & LCC & Cocos $(+)$ & - & - & Homoláctica & + & - & 0 \\
14 & LCC & Bacilos $(+)$ & - & - & Homoláctica & + & - & 0 \\
15 & QFC & Cocos $(+)$ & - & - & Homoláctica & + & - & 0 \\
16 & QFC & Bacilos $(+)$ & - & - & Heteroláctica & + & - & 1 \\
17 & QFC & Bacilos $(+)$ & - & - & Homoláctica & + & - & 0 \\
18 & QFC & Bacilos $(+)$ & - & - & Homoláctica & + & - & 0 \\
\hline
\end{tabular}

Capacidad fermentativa: Las BAL pueden ser divididas fisiológicamente en dos grupos dependiendo de la ruta metabólica que utilicen para fermentar glucosa. De esta manera, las BAL homofermentativas degradan la glucosa vía glucólisis, produciendo principalmente ácido láctico; mientras que las BAL heterofermentativas utilizan la ruta de las pentosas para generar ácido láctico, $\mathrm{CO}_{2}$, ácido acético y/o etanol (Zúñiga et al., 1993). Por lo tanto, el medio de diferenciación M5 (con fructosa) permitió distinguir las cepas homolácticas de las heterolácticas de manera práctica y confiable (Figura 1 y Tabla 1).

Actividad proteolítica: La degradación de las proteínas de la leche constituye uno de los principales procesos durante la maduración de los quesos ya que interviene en la textura final del producto como consecuencia de la degradación del coágulo; también contribuye al desarrollo de aromas y sabores debidos a la liberación de péptidos y aminoácidos de la caseína, que actúan como precursores del aroma en quesos (Marilley y Casey, 2004). Más del $60 \%$ de las cepas lácticas aisladas resultaron positivas, es decir, presentaron coagulación y cambio de color en el primer día de incubación, por acidificación del medio Litmus Milk (Figura 2). Por otro lado, ninguna de las cepas mostró la digestión del medio Litmus Milk, 
indicando que las cepas presentan poca o nula capacidad de degradación proteica, que en nuestro caso es deseable, ya que no se busca alterar importantemente la estructura proteínica del queso fresco (Tabla 1).

Actividad lipolítica, determinación cualitativa: Aunque en general se reconoce que las bacterias lácticas exhiben baja actividad lipolítica, algunos autores han evidenciado que algunas especies poseen enzimas lipasas y/o esterasas, capaces de hidrolizar los triglicéridos y ácidos grasos presentes en la leche, contribuyendo de este modo a la generación de aromas y sabores (Leroy y De Vuyst, 2004; Kongo, 2013). La actividad lipolítica de la totalidad de las cepas aisladas fue evaluada utilizando el medio de cultivo agar nata, sin embargo únicamente dos cepas (5 y 6), presentaron actividad positiva corroborada por la presencia del halo de degradación de grasa alrededor de la colonia (Figura 3).

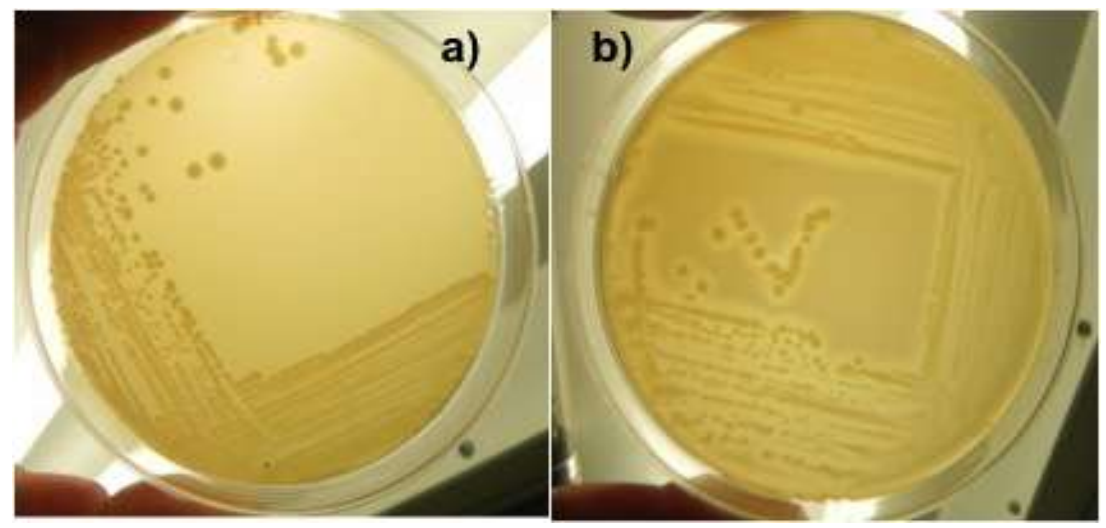

Fig. 3: Comparativo de crecimiento en medio agar nata para detección de actividad lipolítica; a) Prueba negativa y b) Prueba positiva (cepa 6)

Las temperaturas de acción y pH óptimo reportadas para la mayor parte de las lipasas de BAL están comprendidas entre $30^{\circ} \mathrm{C}$ y $40^{\circ} \mathrm{C}$ y un $\mathrm{pH}$ cercano a la neutralidad (Herreros et al., 2003). Por otro lado los lactobacilos presentan actividades de esterasa y lipasa mayores que los lactococos (Delgado et al., 2010; Kongo, 2013)

Prueba de producción de gas: La producción de gas $\mathrm{CO}_{2}$ es especialmente relevante en microorganismos heterofermentativos como producto de la fermentación de azúcares. Sin embargo, también existe producción en especies homofermentativas como resultado del metabolismo del citrato (Castllo et al., 1999). Esta actividad es deseable en quesos de pasta "abierta" o con ojos como el Gruyére, Emmental y Gouda y en quesos azules donde la presencia de cavidades aireadas es necesaria, para permitir el libre desarrollo de los hongos (Chamba y Perréard, 2002). Mientras que en quesos frescos la presencia de cavidades como resultado de producción de gas no es deseable ya que suele asociarse con condiciones de higiene deficientes durante el proceso.

Diferentes autores han confirmado que las $\mathrm{BAL}$ que suelen producir $\mathrm{CO}_{2}$, son principalmente cepas de Leuconostoc spp. (Fox et al., 2000; Piraino et al.,2008). Hasta el momento, los lactobacilos heterofermentativos facultativos, como Lactobacillus paracasei y plantarum, no se han reportado como causantes de defectos en el queso (presencia de ojos o grietas). En este estudio se detectaron bajas actividades de producción de gas para las cepas 8 y 16 que corresponden como se verá más adelante, a especies de Lactobacillus plantarum.

Identificación fenotípica de bacterias lácticas seleccionadas: El sistema miniaturizado API 50 CHL se aplicó a las 18 cepas aisladas, realizándose así el estudio de fermentación de los 49 azúcares contenidos en la galería. Los resultados obtenidos constituyeron el perfil bioquímico y permitieron la identificación microbiana de las cepas autóctonas aisladas. Los géneros identificados fueron Lactobacillus, Lactococcus y Leuconostoc. En la Figura $4 \mathrm{a}$ y $4 \mathrm{~b}$ se detalla la distribución de las cepas por género, para la leche cruda y el queso artesanal, respectivamente.

Se observó que las cepas del género Lactobacillus sp. predominaron en ambas muestras $50 \%$ en queso y $58 \%$ en leche), mientras que para los géneros Lactococcus sp. y Leuconostoc sp. se observaron diferencias entre los tipos de muestra. De esta manera el segundo género en predominio, fueron cepas del género Lactococcus sp. (25\%) en la leche cruda, y cepas del género Leuconostoc sp. (33\%) para las muestras de queso, esto se explica debido a las condiciones de humedad y $\mathrm{pH}$ prevalecientes en cada tipo de muestra. 
Leche cruda de cabra

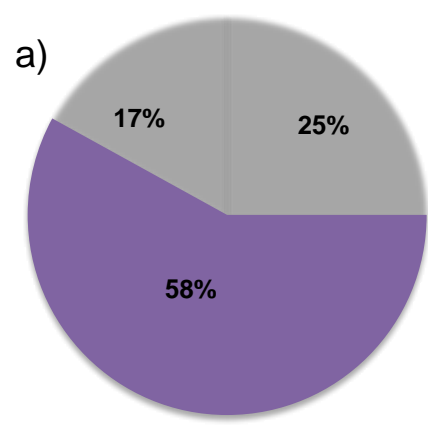

Queso fresco artesanal de cabra

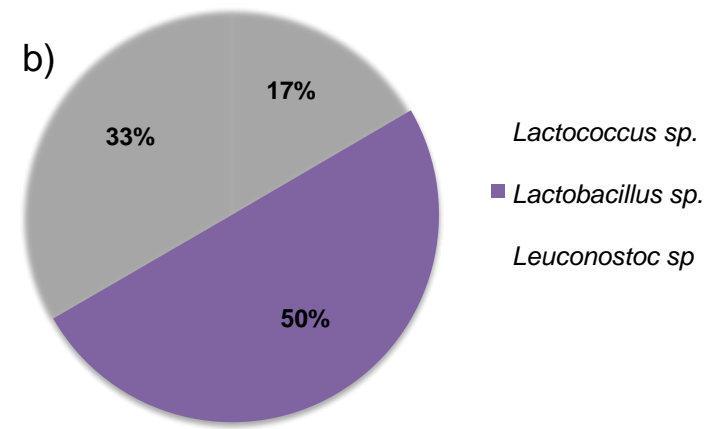

Fig. 4: Distribución porcentual de BAL aisladas de a) leche de cabra y b) queso artesanal.

Comparativamente, Renye et al. (2008) reportaron el aislamiento de bacterias como Lactococcus lactis spp. lactis, Leuconostoc mesenteroides y Enterobacter faecium a partir de quesos elaborados con leche cruda, observándose que este tipo de cepas contribuyeron en el desarrollo de características organolépticas asociadas al queso fresco artesanal. En otro estudio de Saxer et al. (2013), en el que se caracterizó la microflora para algunas variedades de quesos frescos mexicanos industrializados, entre ellos el queso Panela, se reportó que transcurridos 20 días de almacenamiento a $10^{\circ} \mathrm{C}$ la población de bacterias lácticas predominante en queso Panela fue de cepas del género Lactococcus sp., seguida de cepas del género Leuconostoc sp. y por último de cepas de Lactobacillus sp.

Los resultados de la identificación para todas las cepas aisladas, se muestran en la Tabla 2, resaltando que la identificación resultó principalmente a nivel de especie y en solo tres casos a nivel de subespecie. Se aislaron, caracterizaron e identificaron 18 cepas de bacterias lácticas, las cuales fueron adscritas a las siguientes especies: Lactobacillus plantarum (7 cepas), Lactobacilus acidophilus (2 cepas), Lactobacillus paracasei (1 cepa), Lactococcus lactis (4 cepas) y Leuconostoc mesenteroides (4 cepas).

Tabla 2. Identificación fenotípica de las cepas lácticas autóctonas aisladas de leche y queso de cabra.

\begin{tabular}{|c|c|c|c|}
\hline Origen & $\begin{array}{l}\text { Total de cepas } \\
\text { aisladas }\end{array}$ & Código de cepa & Género y especie \\
\hline \multirow{5}{*}{ Leche cruda } & \multirow[t]{5}{*}{12} & $1,11,12$ & Lactococcus lactis ssp. lactis \\
\hline & & 2 & $\begin{array}{l}\text { Lactobacillus paracasei ssp. } \\
\text { paracasei }\end{array}$ \\
\hline & & 5,6 & Lactobacillus acidophilus \\
\hline & & 7,13 & $\begin{array}{l}\text { Leuconostoc mesenteroides ssp. } \\
\text { mesenteroides/dextranicum }\end{array}$ \\
\hline & & $8,9,10,14$ & Lactobacillus plantarum \\
\hline \multirow{3}{*}{$\begin{array}{l}\text { Queso fresco } \\
\text { artesanal }\end{array}$} & \multirow[t]{3}{*}{6} & 3,4 & $\begin{array}{l}\text { Leuconostoc mesenteroides ssp. } \\
\text { mesenteroides/dextranicum }\end{array}$ \\
\hline & & 15 & Lactococcus lactis ssp. lactis \\
\hline & & $16,17,18$ & Lactobacillus plantarum \\
\hline
\end{tabular}

De la información contenida en la tabla anterior se destaca que se recuperaron un menor número de cepas de bacterias lácticas (1/3) en las muestra de queso, esto se atribuye a que durante el proceso de elaboración del queso fresco y como una exigencia normativa para mejorar sus características higiénicas, la leche fue sometida a un proceso térmico de pasteurización. Al respecto, diversos estudios han concluido que los quesos elaborados con leche pasteurizada tienen menos sabor que los elaborados con leche cruda o microfiltrada. Los cambios en la leche causada por la pasteurización incluyen la inactivación de enzimas, ligera desnaturalización de las proteínas del suero y destrucción de la microflora termolábil (Cogan et al., 1997).

Pruebas de antagonismo cruzado: Para poder combinar las cepas de BAL seleccionadas para la formulación de cultivos iniciadores mixtos, es necesario conocer la compatibilidad entre cepas. Por lo que los cultivos utilizados ( 1 y 2 ) fueron compatibles La Figura 5 corresponde al crecimiento en placa para la cepa 1 (Lactococcus lactis ssp lactis), en la que se observa que el sobrenadante libre de células de la cepa 6 (Lactobacillus acidophilus) produce un halo de inhibición. Por lo tanto, esta prueba manifiesta que la combinación de éstas cepas en un cultivo iniciador mixto no es factible. 
Curvas de acidificación: Con el objetivo de identificar las cepas que tienen mayor poder acidificante, realizamos las curvas con respecto al tiempo de acidificación cuantificadas como descenso de pH (Figura 6a) y producción de ácido láctico (Figura 6b) para las cepas que cuajaron totalmente el Litmus Milk el primer día de incubación. Observándose que las cepas más acidificantes son las correspondientes a 2 y 11 (Lactobacillus paracasei ssp paracasei y Lactococcus lactis ssp lactis, respectivamente). Por el contrario la cepa 5 (Lactobacillus acidophilus) fue la menos acidificante y la menos productora de ácido láctico. La cinética de disminución de $\mathrm{pH}$ fue un factor que se consideró para la selección de las BAL, pues el queso artesanal presenta un $\mathrm{pH}$ bajo. Se sabe que el $\mathrm{pH}$ bajo inhibe el crecimiento de microorganismos indeseables y patógenos.

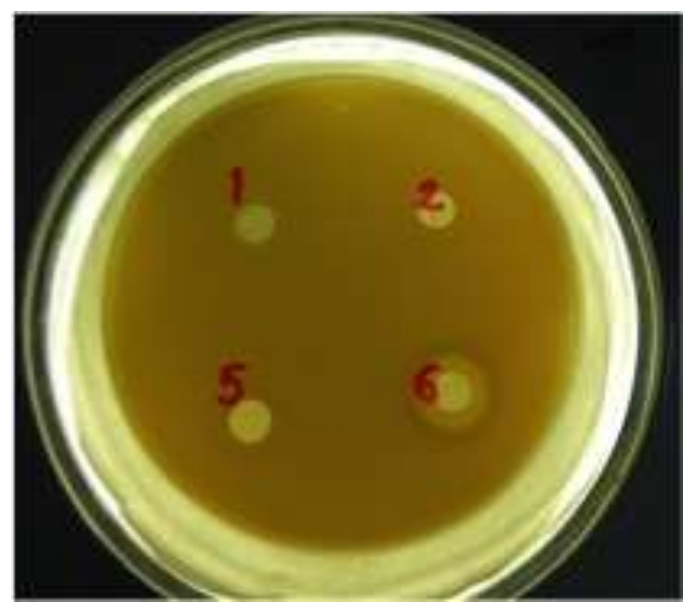

Fig. 5. Prueba de antagonismo cruzado cepa 1 (Lactococcus lactis ssp lactis).

a)

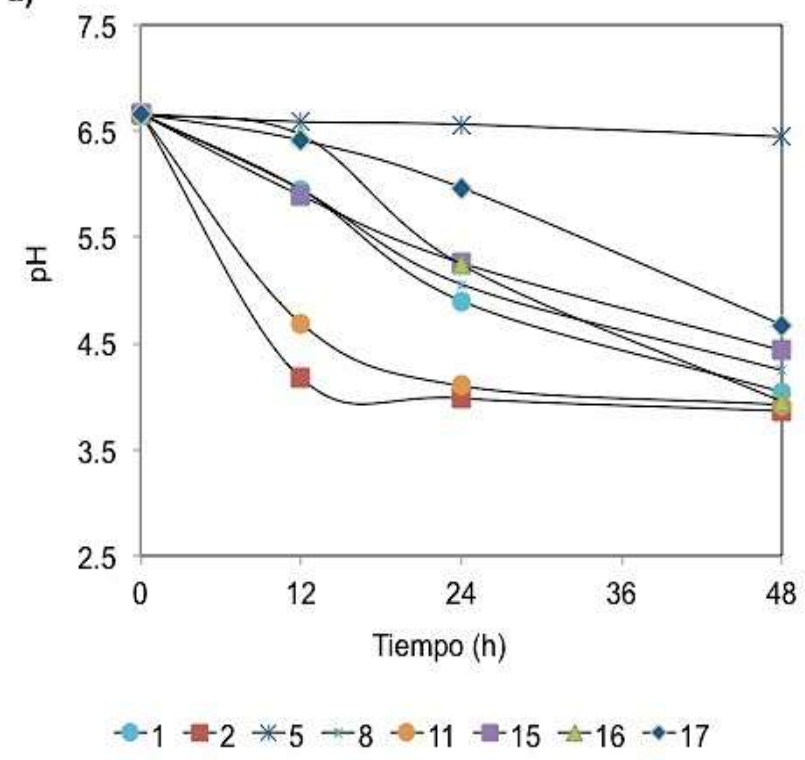

b)

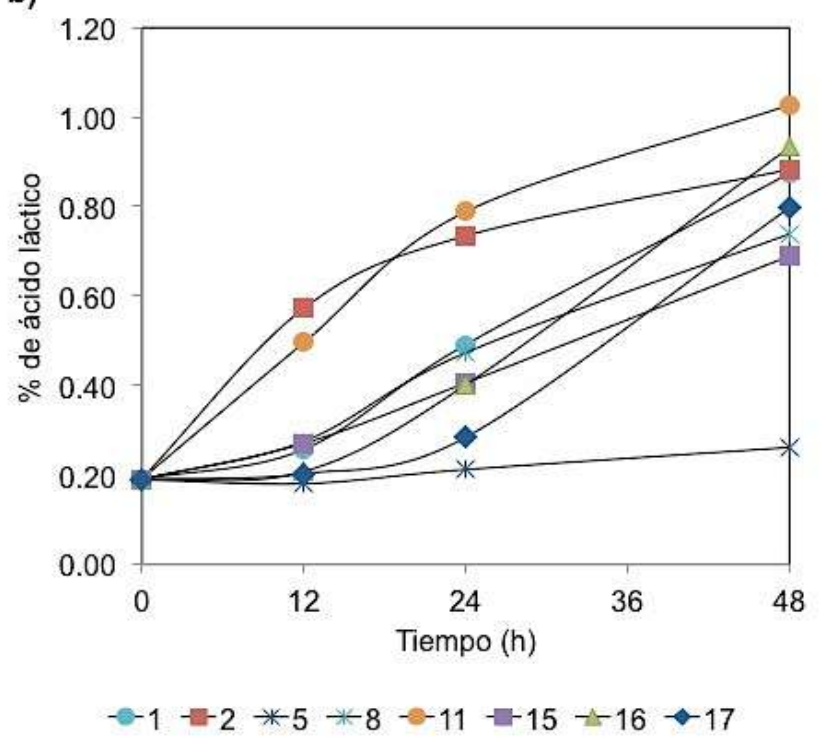

Fig. 6: a) Curva de descenso de pH; b) Curva de producción de ácido láctico.

Las principales diferencias en el poder acidificante de las cepas fueron encontradas en las primeras 12 horas de incubación de la leche, coincidiendo con las observaciones realizadas por Chacón-Rueda y López Corcuera (2000). Este comportamiento fue similar al cabo de 24 horas; las diferencias en los valores de pH entre la cepa más y la menos acidificante fue de aproximadamente 1 unidad de $\mathrm{pH}$. Este valor coincide con lo observado por Herreros et al. (2003) durante la caracterización tecnológica de cepas aisladas de queso de cabra.

En la Tabla 3 se presentan los resultados puntuales, a 3 tiempos del seguimiento, del descenso de pH y producción de ácido láctico obtenidos en la prueba de poder acidificante de BAL aisladas. La mayoría de los autores coincide que las cepas adecuadas para la formulación de cultivos iniciadores son aquellas que producen hasta $25^{\circ}$ Dornic $(0.25 \%$ de ácido láctico) o pH menor a 5.4, después de $6 \mathrm{~h}$ de incubación a $30^{\circ} \mathrm{C}$, ya que estarían asegurando una correcta acidificación y por otro lado evitando la proliferación de microbiota indeseable (Karimi et al., 2012). En el caso del queso fresco, se espera que la adición de cepas autóctonas no disminuya su valor de pH a menos de 5.4. 
De acuerdo a Casalta et al. (1995) las cepas de Lactococcus sp. son frecuentemente incluidas en los cultivos de quesería debido a que acidifican rápidamente, lo cual de acuerdo a Karimi et al. (2012), cobra importancia debido a que la disminución rápida del $\mathrm{pH}$ de la cuajada inhibe el desarrollo de microorganismos indeseables. En un estudio realizado por Alonso-Calleja et al. (2002), las cepas de lactococos fueron divididas en dos grupos en función de la velocidad de producción de ácido; las cepas rápidas coagularon el medio en menos de $18 \mathrm{~h}$, mientras las cepas lentas necesitaron al menos 36 horas para formar el coágulo. Bajo este criterio las cepas de lactococos aisladas en el presente estudio quedan clasificadas como rápidas.

Tabla 3. Resultados de la prueba de poder acidificante para las BAL a las 12, 24 y 48 horas de cultivo.

\begin{tabular}{cccccccc}
\hline \multirow{2}{*}{ Cepa } & \multicolumn{5}{c}{$\mathrm{pH}$} & \multicolumn{5}{c}{ Acidez $(\%$ ácido láctico) } & $V m(\Delta \mathrm{pH} / 24 \mathrm{~h})$ \\
\cline { 2 - 7 } 1 & $12 \mathrm{~h}$ & $24 \mathrm{~h}$ & $48 \mathrm{~h}$ & $12 \mathrm{~h}$ & $24 \mathrm{~h}$ & $48 \mathrm{~h}$ & $24 \mathrm{~h}$ \\
\cline { 2 - 7 } 2 & 5.95 & 4.90 & 4.04 & 0.26 & 0.49 & 0.87 & -0.07 \\
3 & 4.18 & 3.98 & 3.86 & 0.57 & 0.73 & 0.88 & -0.11 \\
4 & 5.52 & 5.52 & 5.37 & 0.20 & 0.20 & 0.28 & -0.05 \\
5 & 6.17 & 6.12 & 5.90 & 0.20 & 0.20 & 0.28 & -0.02 \\
6 & 6.59 & 6.56 & 6.45 & 0.18 & 0.21 & 0.26 & 0.00 \\
7 & 5.39 & 5.92 & 4.53 & 0.19 & 0.27 & 0.72 & -0.03 \\
8 & 5.45 & 4.25 & 4.38 & 0.26 & 0.40 & 0.70 & -0.10 \\
9 & 5.67 & 5.06 & 4.25 & 0.27 & 0.47 & 0.74 & -0.07 \\
10 & 5.83 & 5.23 & 4.31 & 0.26 & 0.30 & 0.82 & -0.10 \\
11 & 4.69 & 4.10 & 3.92 & 0.50 & 0.79 & 1.03 & -0.11 \\
12 & 5.79 & 4.18 & 3.97 & 0.35 & 0.65 & 0.95 & -0.10 \\
13 & 6.30 & 5.86 & 4.72 & 0.20 & 0.28 & 0.80 & -0.03 \\
14 & 6.41 & 5.32 & 4.18 & 0.26 & 0.46 & 0.73 & -0.06 \\
15 & 5.89 & 5.26 & 4.43 & 0.27 & 0.41 & 0.69 & -0.06 \\
16 & 6.46 & 5.24 & 3.95 & 0.21 & 0.40 & 0.93 & -0.06 \\
17 & 6.41 & 5.97 & 4.68 & 0.20 & 0.28 & 0.80 & -0.03 \\
18 & 6.41 & 5.89 & 4.48 & 0.20 & 0.27 & 0.78 & -0.03 \\
\hline
\end{tabular}

\section{Parámetros cinéticos}

a) Velocidad máxima de acidificación: La velocidad de acidificación $(\mathrm{Vm})$, de la leche o de la mezcla cuajada-suero durante la elaboración del queso, es característico de cada cultivo y depende principalmente de la temperatura (Oliszewski, 2006). De esta manera, a partir de las curvas de acidificación se puede conocer el tiempo para llevar el pH de 6 a 5.5. Las pruebas de acidificación realizadas en esta investigación mostraron que más del $60 \%$ de las cepas aisladas coagularon la leche en menos de 24 horas; 3 dentro de las primeras 12 horas y otras 8 dentro de las 12 siguientes (11 cepas en total, en 24 horas), e indicando también que algunas cepas utilizarían más tiempo del que se requiere para la producción del queso fresco, para lograr el descenso a un pH de 5.5, que fue el caso en 7 de las 7 cepas restantes caracterizadas.

Con respecto a la velocidad de acidificación a las 24 horas, dato incluido en la tabla anterior, dos de las 18 cepas aisladas presentaron los valores más altos $(\mathrm{Vm}=-0.11)$ y corresponden a la cepa 2 (Lactobacillus. paracasei ssp. paracasel) y la cepa 11 (Lactococcus lactis ssp. lactis); seguidas por la cepa 7 (Leuconostoc mesenteroides) con un valor para $\mathrm{Vm}=-0.10$. En términos generales se puede considerar que las condiciones de acidificación deseables para un cultivo iniciador son aquellas que promueven valores mínimos de $\mathrm{Vm}$, es decir que valores de $\mathrm{Vm}$ negativos generan menores tiempos de proceso y mayor capacidad de producción. Por otro lado la capacidad de acidificación expresada como pH de la leche al momento de la coagulación, mostró que Lactobacillus. paracasei ssp paracasei provocó un descenso de $\mathrm{pH}$ de 6.7 a 4.18 en las primeras 12 horas, llegando a un pH de 3.86 a las 48 horas; en tanto que las cepas 8 y 17 de Lactobacillus plantarum produjeron valores de $\mathrm{pH}$ de 5.95 y 6.41 , generando valores finales de $\mathrm{pH}$ de 4.25 y 4.68 , respectivamente.

b) Cinética de crecimiento: En la Figura 7 se muestran las curvas de crecimiento con respecto al tiempo (0, 6, 12, 24, 48 y 72 horas) para 5 de las cepas BAL seleccionadas (cepas 2, 6, 8, 11 y 16), con base a las propiedades tecnológicas antes descritas y a su compatibilidad de acuerdo a los resultados de las pruebas de antagonismo cruzado. 
En la Tabla 4, se muestran los parámetros cinéticos para las cepas seleccionadas, derivados de la aplicación del modelo de crecimiento primario de Baranyi y Roberts (1994), expresado tanto por el conteo o concentración inicial $\left(\mathrm{Cl}, \log _{10} \mathrm{UFC} / \mathrm{mL}\right)$ como su crecimiento microbiano final (CC, $\left.\log _{10} \mathrm{UFC} / \mathrm{mL}\right)$. De igual manera, se determinó la tasa de crecimiento máxima ( $\mu$ máx, $\mathrm{h}^{-1}$ ), observándose los valores más altos $(>0.35$ $\mathrm{h}^{-1}$ ) para las cepas 2, 8 y 11 (Lactobacillus paracasei ssp. paracasei, Lactobacillus plantarum y Lactococcus lactis ssp. lactis) y menores tasas de crecimiento $\left(0.24 \mathrm{~h}^{-1}\right.$ y $\left.0.35 \mathrm{~h}^{-1}\right)$ para las cepas 6 (Lactobacillus acidophilus) y la cepa 16 (Lactobacillus plantarum). Así mismo se expresan los resultados para el coeficiente de regresión $\left(R^{2}\right)$ y el error estándar del ajuste (ES).

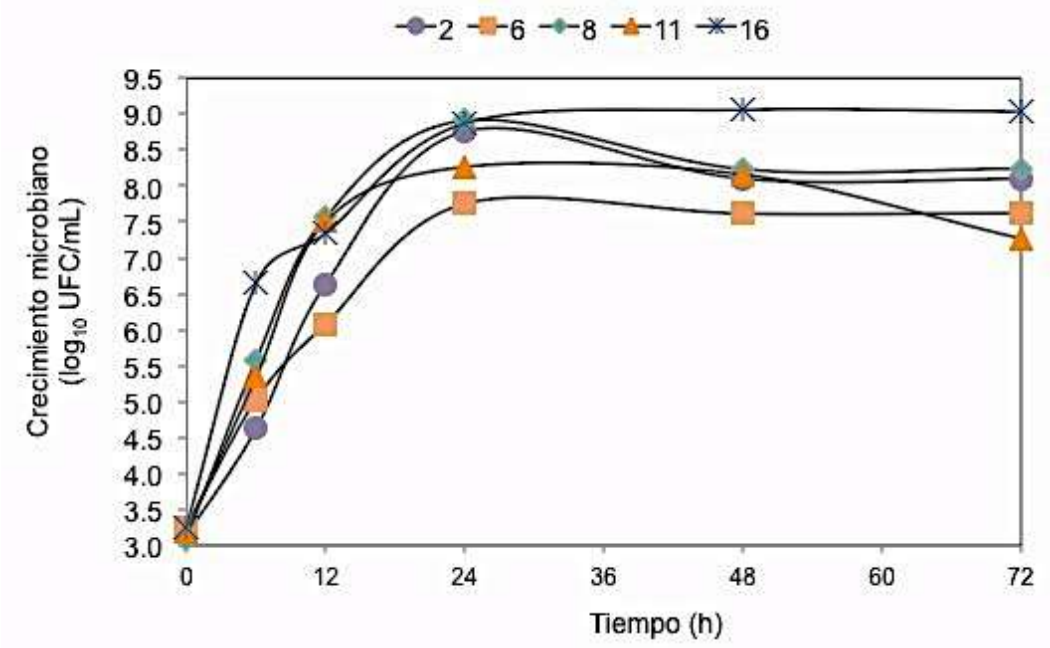

Fig. 7. Cinética de crecimiento para las BAL seleccionadas.

Tabla 4. Parámetros cinéticos para las BAL seleccionadas.

\begin{tabular}{cccccc}
\hline Cepa & $\begin{array}{c}\mathrm{CC} \\
\log _{10} \mathrm{UFC} / \mathrm{mL}\end{array}$ & $\begin{array}{c}\mu_{\text {máx }} \\
\left(\mathrm{h}^{-1}\right)\end{array}$ & $\begin{array}{c}\mathrm{Cl} \\
\log _{10} \mathrm{UFC} / \mathrm{mL}\end{array}$ & $\mathrm{R}^{2}$ & ES \\
\cline { 2 - 6 } 2 & $8.158 \pm 0.072$ & $0.398 \pm 0.013$ & $2.235 \pm 0.094$ & 0.998 & 0.102 \\
6 & $7.666 \pm 0.106$ & $0.238 \pm 0.022$ & $3.372 \pm 0.165$ & 0.990 & 0.180 \\
8 & $8.458 \pm 0.191$ & $0.386 \pm 0.046$ & $3.149 \pm 0.309$ & 0.977 & 0.332 \\
11 & $7.904 \pm 0.259$ & $0.377 \pm 0.071$ & $3.163 \pm 0.426$ & 0.948 & 0.451 \\
16 & $8.975 \pm 0.365$ & $0.354 \pm 0.081$ & $3.657 \pm 0.582$ & 0.922 & 0.631 \\
\hline
\end{tabular}

\section{Consideraciones finales}

Con base en los resultados de caracterización de las bacterias lácticas autóctonas y tomando en cuenta que en productos fermentados tipo queso, el Codex internacional exige que se mantenga una concentración mínima de $10^{6} \mathrm{UFC} / \mathrm{g}$ (Codex, 2015), los valores obtenidos son aceptables para la formulación de cultivos iniciadores. A partir de las cepas seleccionadas en este estudio, se formularon cultivos iniciadores mixtos, los cuales fueron posteriormente incorporados en el proceso de elaboración de queso fresco, evaluando de esta manera su efecto sobre diversos aspectos tales como, calidad microbiológica, textura, olor y sabor, y parámetros fisicoquímicos. (Datos no publicados).

\section{CONCLUSIONES}

Como resultado de las pruebas realizadas se lograron aislar, caracterizar e identificar 18 cepas de bacterias lácticas autóctonas a partir de leche y queso artesanal de cabra. Las cuales correspondieron a 7 cepas de Lactobacillus plantarum, 2 cepas de Lactobacillus acidophilus 1 cepa de Lactobacillus paracasei spp., 4 cepas de Lactococcus lactis spp. y 4 cepas de Leuconostoc mesenteroides spp. Las diferentes pruebas permitieron diferenciar su actividad metabólica y funcional, lo cual constituye un conocimiento valioso para la aplicación de nuevos cultivos iniciadores. De igual manera las pruebas de antagonismo cruzado resultaron útiles para conocer la compatibilidad entre cepas en la formulación cultivos mixtos. Finalmente, a partir de los parámetros cinéticos evaluados, es posible inferir el desempeño de las cepas lácticas, permitiendo con ello mejorar el control sobre los procesos y mejorando la vida útil y calidad microbiológica del producto lácteo terminado. 


\section{AGRADECIMIENTOS}

La autora Carolina Ramírez López, agradece a la Universidad de las Américas Puebla y al Consejo Nacional de Ciencia y Tecnología (CONACyT, México) por el financiamiento recibido para la realización de este trabajo. Así mismo al Centro de Investigación en Biotecnología Aplicada del Instituto Politécnico Nacional (CIBA-IPN) por el soporte técnico para la caracterización microbiológica de las cepas aisladas.

\section{REFERENCIAS}

Alonso-Calleja, C., Carballo, J., Capita, R., Bernardo, A. y García-López, M.L. Comparison of acidifying activity of Lactococcus lactis subsp. lactis strains isolated from goat's milk and valdeteja cheese. Letter Applied Microbiology, 34,134-138 (2002)

AOAC Official Methods of Analysis. Edición 18. AOAC International, Gaithersburg, MD, USA. (2005)

Asteri, I. A., Robertson, N., Kagkli, D. M., Andrewes, P., Nychas, G., Coolbear, T., Holland, R., Crow, V., y Tsakalidou, E. Technological and flavour potential of cultures isolated from traditional Greek cheeses- a pool of novel species and starters. International Dairy Journal, 19, 595-604 (2009)

Baranyi, J. y Roberts, T. Mathematics of predictive food microbiology. International Journal of Food Microbiology, 26,199-218 (1995)

Casalta, E., Vassal, Y., Desmazeaud, M.J., y Casablanca, F. Comparaison de l'activitée acidifiante de souches de Lactoccocus lactis isolées de latí de corse. Lebensmittel-Wissenschaft un Technologie, 28, 291299 (1995)

Cayré, M.E., Vignolo, G.M., y Garro, O.A. Selección de un modelo primario para describir la curva de crecimiento de bacterias lácticas y Brochothrix thermosphacta sobre emulsiones cárnicas cocidas. Información Tecnológica, 18 (3), 23-29 (2007)

Chacón-Rueda, Z. y López-Corcuera, G. Evaluación de cepas de Lactococcus como cultivos iniciadores en la elaboración de quesos de pasta prensada. Revista Científica, FCV-LUZ, 10 (5), 423-428 (2000)

Chamba, J.F. y Perréard, E. Contribution of propionibacteria to lipolysis of Emmental cheese. Lait, 82, 33-44 (2002)

Codex Alimentarius. Leche y Productos Lácteos. Segunda edición. Organización Mundial de la Salud. Organización de las Naciones Unidas para la Alimentación y la Agricultura. pp. 71. Roma 2011. http://www.fao.org/docrep/015/i2085s/i2085s00.pdf. [Fecha de acceso 04/11/15] (2015)

Cogan, T.M., Barbosa, M., Beuvier, E., Bianchi-Salvadori, B., Cocconcelli, PS., Fernandes, I., Gomez, J., Gomez, R., Kalantzopoulos, G., Ledda, A., Medina, M. Rea M.C. y Rodriguez, E. Characterization of the lactic acid bacteria in artisanal dairy products. Journal of Dairy Research, 64, 409-421 (1997)

Delgado, F. J., González-Crespo, J., Cava, R., García-Parra, J. y Ramírez, R. Characterisation by SPMEGC-MS of the volatile profile of a Spanish soft cheese P.D.O. Torta del Casar during ripening. Food Chemistry, 118, 182-189 (2010)

DeMan, J., Rogosa, M. y Scharpe, M.E. A medium for the cultivation of lactobacilli. Journal of Applied Bacteriology, 23, 130-135 (1972)

De Roissart, H. y Luquet, F.M. Bacteries lactiques Aspects Fondamentaux et Technologiques. 2a edición, Lorica Uriage, Francia (1994)

Ferrer, J., Prats, C. López, D. y Vives-Rego, J. Mathematical modelling methodologies in predictive food microbiology: A SWOT analysis. International Journal of Food Microbiology, 134, 2-8 (2009)

Fox, P.F., Guinne, T.P., Timothy, M.C. y McSweeney P.L.H. Fundamentals of Cheese Science. Aspen Publishers, 392 - 422, Maryland, USA. (2000)

Fraga-Cotelo, M., Perelmuter-Schein, K., Giacaman-Salvo, S.S., Zunino-Abirad, P.M. y Carro-Techera, S.B. Antimicrobial properties of lactic acid bacteria from Uruguayan artisan cheese. Food Science Technology, Campinas, 33 (4), 801-804 (2013) 
González, L. y Zárate V. Influence of an autochthonous starter culture and a commercial starter on the characteristics of Tenerife pasteurised goats' milk cheese. International Journal of Dairy Technology, 65 (4), 542-547 (2012)

Herreros, M.A, J.M Fresno, González-Prieto, M.J. y Tornadijo, M.E. Technological characterization of lactic acid bacteria isolated from Armada cheese. International Dairy Journal, 13 (6), 469-479 (2003)

International Dairy Federation. Bulletin of the IDF No. 306/1995. Fermented and Non-Fermented Milk Products: Detection and Enumeration of Lactobacillus acidophilus. IDF Guideline. Determination of Acidifying Activity of Dairy Cultures (1995)

Jackson, M.S., Bird A.R. y McOrist A.L. Comparison of two selective media for the detection and enumeration of Lactobacilli in human faeces. Journal of Microbiological Methods, 51, 313-321 (2002)

Karimi, R., Mortazavian, A.M. y Amiri-Rigi, A. Selective enumeration of probiotic microorganisms in cheese, Food Microbiology, 29, 1-9 (2012)

Kongo, J.M. Lactic acid bacteria as starter-cultures for cheese processing: Past, present and future developments. En: Lactic Acid Bacteria-R\&D for Food, Health and Livestock purposes. Editor Kongo M. InTech. DOI: 10.5772/2825. 658 pp (2013)

Leroy, F. y De Vuyst, L. Lactic acid bacteria as functional starter cultures for the food fermentation industry. Trends in Food Science and Technology, 15 (2), 67-78 (2004)

Marilley, L. y Casey, M.G. Flavours of cheese products: metabolic pathways, analytical tools and identification of producing strains. International Journal of Food Microbiology, 90, 139-159 (2004)

Mayeux, J.V., Sandine, W.E. y Elliker P. R. A selective medium for detecting Leuconostoc organims in mixed-strain starter cultures. Journal of Dairy Science, 45, 665 (1962)

Morais, J. Estudio de adecuación de cepas lácticas autóctonas aisladas de leche cruda de oveja guirra para la elaboración de queso. Tesis de Doctorado. Facultad de Veterinaria. Departamento de Ciencia Animal y de los Alimentos. Universidad Autónoma de Barcelona, Barcelona, España (2004)

Nikolic, M., Terzic-Vidojevic, A., Jovcic, B., Begovic, J., Golic, N. y Ljubisa, T. Characterization of lactic acid bacteria isolated from Bukuljac, a homemade goat's milk cheese. International Journal of Food Microbiology, $122(1-2), 162-170(2008)$

Oliszewski, R. Leche de cabra: su calidad y evaluación de starters lácticos caprinos regionales en la manufactura de productos fermentados. Tesis doctoral. Facultad de Agronomía y Zootecnia. Universidad Nacional de Tucumán. Tucumán. Argentina (2006)

Pavunc, A.L., Beganovi J., Kos B., Uroic K., Blazic M. y Suskovic J. Characterization and application of autochthonous starter cultures for fresh cheese production. Food Technology and Biotechnolgy, 50 (2), 141151 (2012)

Pérez-Erlotondo, F.J., Aldámiz-Echobarria, P.A., Albisu, M. y Barcina, Y. Indigenous lactic acid bacteria in Idiazábal ewe's milk cheese. International Dairy Journal, 8, 725-732 (1998)

Perin, L.M., y Nero, L.A. Antagonistic lactic acid bacteria isolates from goat milk and identification of a novel nisin variant Lactococcus lactis. BMC Microbiology, 14, 36 (2014)

Piraino, P., Zotta, T., Ricciardi, A., McSweeney, P.L.H. y Parente E. Acid production, proteolysis, autolytic and inhibitory properties of lactic acid bacteria isolated from pasta filata cheeses: $A$ multivariate screening study, International Dairy Journal, 18, 81-92 (2008)

Renye, J.A., Somkuti, G.A., Vallejo-Cordoba, B., Van Hekken, D.L. y Gonzalez-Cordova, A.F. Characterization of the microflora isolated from Queso Fresco made from raw and pasteurized milk. Journal of Food Safety, 28, 59-75 (2008)

Rogosa, M., Mitchel, J.A., y Wiseman, R.F. A selective medium for the isolation of oral and faecal Lactobacilli. Journal of Bacteriology, 62, 132-133 (1951)

Rosso, J., Lobry, J.R., Bajard, S. y Flandrois, J.P. Convenient model to describe the combined effects of temperature and $\mathrm{pH}$ on microbial growth. Applied and Environmental Microbiology, 61,610-616 (1995) 
Saxer, S., Schwenninger, S.M. y Lacroix, C. Characterization of the microflora of industrial Mexican cheeses produced without added chemical preservatives. Food Science and Technology, 53, 314-320 (2013)

Settanni, L. y Moschetti, G. Non-starter lactic acid bacteria used to improve cheese quality and provide health benefits. Food Microbiology, 27, 691-697 (2010)

Speranza, B., Bevilacqua, A., Corbo, M.R., Altieri, C. y Sinigaglia, M. Selection of autochthonous strains as promising starter cultures for Fior di Latte, a traditional cheese of southern Italy, Journal of Science and Food Agriculture, 95, 88-97 (2015)

Sun-Waterhouse, D., Zhou, J. y Wadhwa, S. S. Drinking yoghurts with berry polyphenols added before and after fermentation. Food Control, 32, 450-460 (2013)

Terzaghi, B.E., y Sandine, W.E. Improved medium for lactic streptococci and their bacteriophages. Applied Microbiology, 29, 807-813 (1975)

Terzic-Vidojevic, A., Mihajlovic, S., Uzelac, G., Veljovic, K. Tolinacki, M., Nikolic, M., Topisirovic, L. y Kojic, M. Characterization of lactic acid bacteria isolated from artisanal Travnik young cheeses, sweet creams and sweet kajmaks over four seasons. Food Microbiology, 39, 27-38 (2013)

Vásquez, M.S.M., Suárez, M.H. y Zapata, B.S. Utilización de sustancias antimicrobianas producidas por bacterias acido lácticas en la conservación de la carne. Revista Chilena de Nutrición, 36 (1), 64-71. (2009)

Zúñiga, M., Pardo I. y Ferrer, S. An improved medium for distinguishing between homofermentative and heterofermentative lactic acid bacteria. International Journal of Food Microbiology, 18 (1), 37- 42 (1993) 